\title{
UPDATE ON DIFFUSION-TREATED Corundum: ReD AND OTHER COLORS
}

\author{
By Shane F. McClure, Robert C. Kammerling, and Emmanuel Fritsch
}

Blue diffusion-treated sapphires have become a subject of considerable controversy since their introduction in significant quantities a few years ago. Now it appears that diffusion-treated corundum in additional colors, including red, may also be a commercial reality in the near future. At the request of the treater, the authors examined faceted specimens in a range of colors to document their gemological properties and determine identification criteria prior to any commercial release. Diagnostic features include unusually high refractive-index readings, atypical dichroism, atypical luminescence, patchy surface coloration, color concentrations along facet junctions, and spherical voids just below the surface.

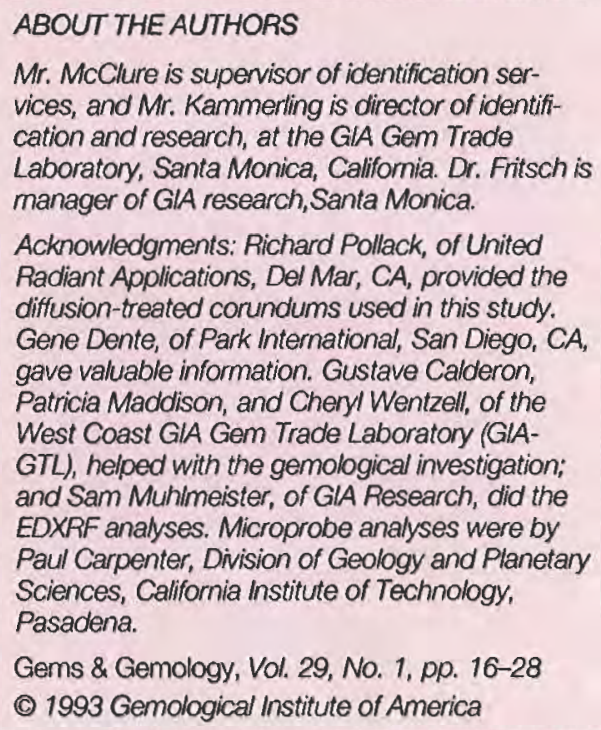

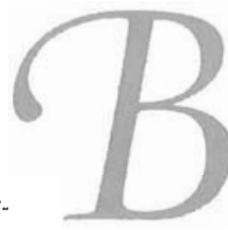

lue diffusion-treated sapphires, little more than a gemological curiosity in the late 1970s and early 1980s, became a significant-and controversial-commercial reality at the start of this decade (Kammerling et al., 1990; Koivula and Kammerling, 1990|. A detailed study of these stones was reported in Kane et al. (1990).

Since then, there have been a number of developments in the area of blue diffusion-treated sapphires. First, a significant amount of the material has reportedly entered the trade ("Diffusion: 80,000 carats in Asia," 1991; Koivula et al., 1992a). Second, the strong demand for calibrated stones in a number of traditional cuts indicates an acceptance of the product by at least some large-scale manufacturing jewelers and retailers (Koivula and Kammerling, 1991a; Koivula et al., 1992a; Federman, 1992). Blue diffusion-treated stones have also become available commercially in a broad range of sizes, from $0.12 \mathrm{ct}$ ( $3 \mathrm{~mm}$ rounds) to over $50 \mathrm{ct}$ (Koivula et al., 1992a). The GIA Gem Trade Laboratory has seen some diffusiontreated sapphires set in fine jewelry (see, e.g., Hargett, 1991). Although pale-to-colorless corundum from Sri Lanka has been the preferred starting material for diffusion-treated stones, gem-testing laboratories have recently examined treated faceted stones from Montana and flame-fusion synthetic material (Kammerling et al., 1992; Lithiby, 1992) that has been diffusion treated blue.

Not all developments in diffusion treatment, however, have been restricted to producing blue stones. Experiments related to U.S. Patent 3,897,529 (Carr and Nisevich, 1975; reviewed in Kane et al., 1990) describe "ruby red," "salmon pink," and pink colors, among others, being produced by diffusion treatment of various pale or unevenly colored specimens of corundum. In fact, the first example of diffusion-treated corundum examined in the GIA Gem Trade Laboratory was red-orange (Crowningshield, 1979).

More recently, in early 1991, Jeffrey Bergman of Gem Source reported that attempts to produce red colors by the 


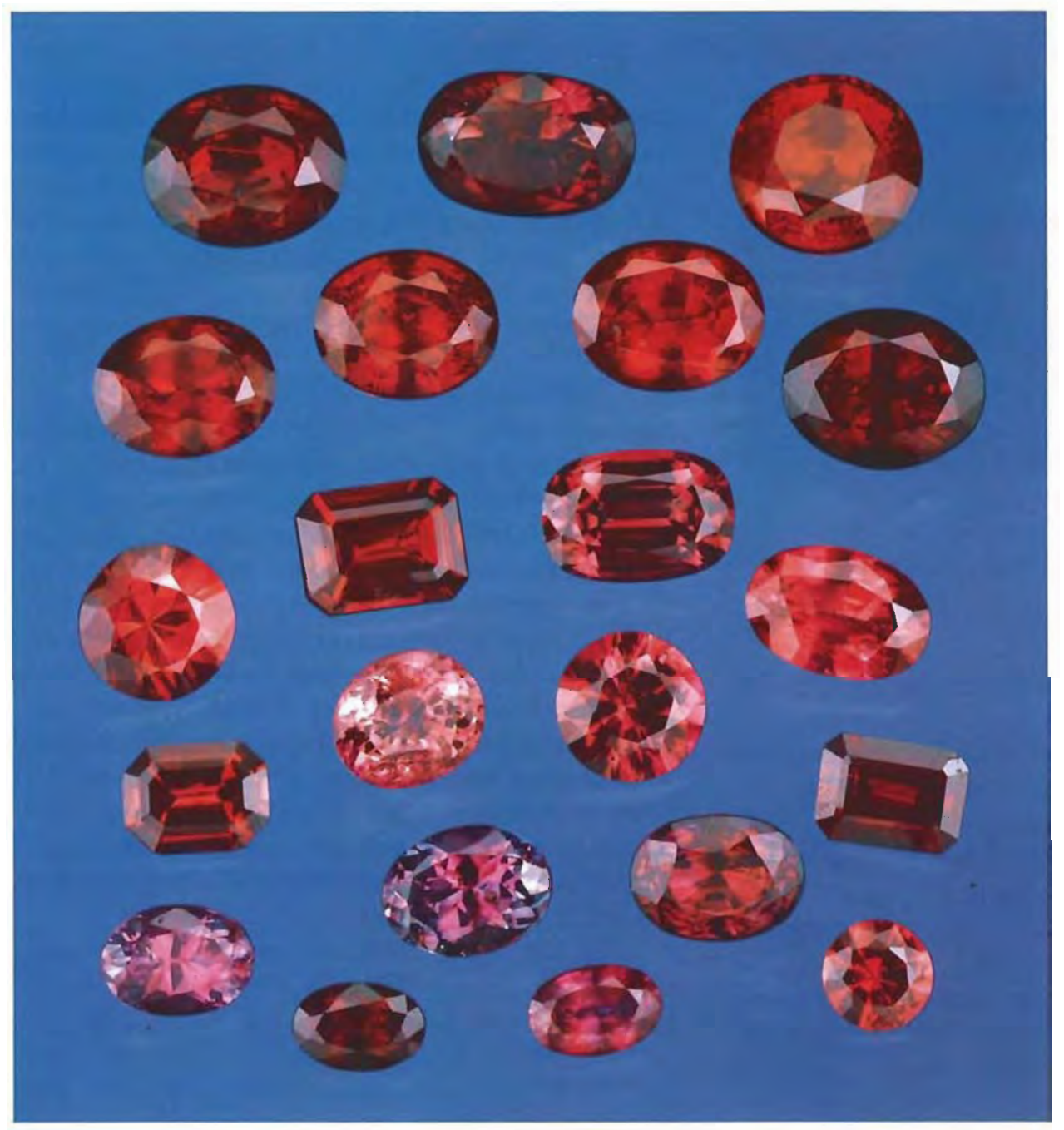

Figure 1. These stones, ranging from 0.55 to 5.67 $c t$, represent a range of colors that are now being produced by diffusion treatment of corundum. This material is being processed for eventual release to the jewelry trade. Photo by Shane F. McClure.

diffusion process had been unsuccessful: The result was very shallow penetration of the red-producing chromophore, as well as the development of an unwanted blue component (Koivula and Kammerling, $1991 \mathrm{a}, \mathrm{c})$. Other dealers involved in red diffusion-treatment experimentation have reported similar difficulties, producing at best a pink overall body color after the necessary repolishing (Koivula et al., 1992a). Most recently, however, an isolated 0.48-ct corundum reportedly diffusion treated to a "rich cherry-red colour" was identified at the Asian Gemmological Laboratory in Hong Kong ("Diffusion-treated red corundum in HK," 1992).

In late 1992, the authors were contacted by Richard Pollack, of United Radiant Applications, who has been involved in the commercial production of blue diffusion-treated sapphires since 1989 (and was responsible for producing many of the stones examined in the Kane et al., 1990, study). He informed us that he had succeeded in producing diffusion-treated conun- dum in the pink-to-red color range (figure 1) and that such stones might soon be commercially viable. Before they were released into the trade, however, Mr. Pollack wished to have the product thoroughly documented gemologically and identification criteria established to discourage any subsequent misrepresentation of loose or jewelry-set stones (figure 2). At the time he provided the research samples, he reaffirmed that he would not distribute this material commercially until the report had been published.

\section{THE DIFFUSION-TREATMENT PROCESS}

The process used to diffuse surface color into corundum is reviewed in Kane et al. (1990). In the most basic terms, the process usually involves embedding fashioned stones in a powder consisting of aluminum oxide plus coloring agent(s) within an alumina crucible. Extended heating of the crucible in a furnace at elevated temperatures-typically $1600^{\circ} \mathrm{C}-1850^{\circ} \mathrm{C}$, but at times approaching the melting point of corundum 


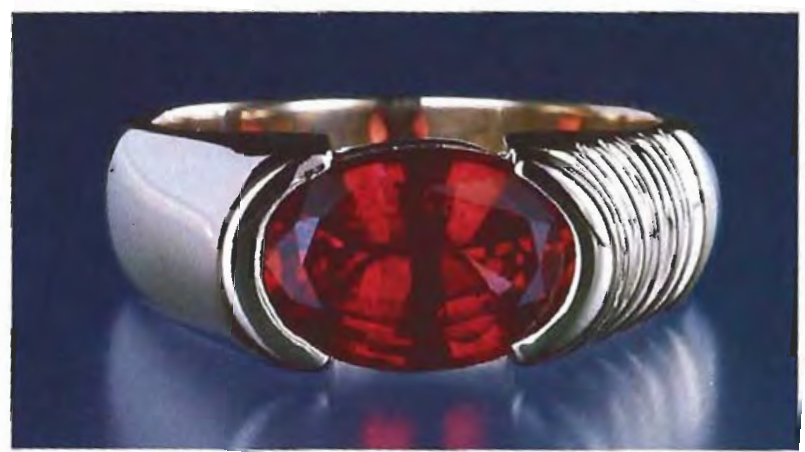

Figure 2. The jewelry potential of xed diffusiontreated corundum is well illustrated by this mounted 4+ct stone. Photo by Shane F. Mcclure.

$\left(2050^{\circ} \mathrm{C}\right)$-results in a zone of treated color near the surface of the stone.

To produce a blue diffusion layer, oxides of iron and titanium are typically used, although cobalt has been used at least experimentally (Kane et al., 1990). Chromium oxide would appear to be the most logical chromophore for producing pink to red, as $\mathrm{Cr}^{3+}$ is the principal coloring agent in ruby and pink sapphire (Fritsch and Rossman, 1988). Among the early diffusion-treatment experiments that resulted in pink to red colors, one used a combination of $3 \%-6 \%$ chromium oxide and $22 \%-24 \%$ titanium oxide (Carr and Nisevich, 1975).

\section{DISCLOSURE AND \\ NOMENCLATURE ISSUES}

Although there is no unanimity in the gem trade concerning proper nomenclature for disclosing diffusion treatment, there is general agreement that the treatment should be disclosed. The GIA Gem Trade Laboratory currently uses the following wording in the conclusion of an identification report for a blue diffusion-treated sapphire:

\section{DIFFUSION-TREATED NATURAL SAPPHIRE}

Note: The color of this stone is confined to a shallow surface layer that has been produced by diffusing chemicals into the surface by heat treatment.

The word natural is used to avoid confusion with synthetic sapphires which, as noted above, may also be diffusion treated. Furthermore, the word sapphire refers to the starting material, which-regardless of its color-would be classified as such.

Red diffusion-treated material, however, presents a more complicated situation. Although the starting gem material is sapphire, the end product may resemble ruby. To call such material "diffusion-treated ruby" misrepresents the starting material; yet to call it "diffusion-treated sapphire" would be confusing at best. Should such a stone be submitted to the GIA Gem Trade Laboratory, we would probably use the more generic term diffusion-treated conundum.

\section{MATERIALS AND METHODS}

The study sample on which this report is based included 43 faceted stones ranging from 0.41 to $5.67 \mathrm{ct}$. Twelve of the stones were "ruby color," according to GIA Gem Trade Laboratory criteria (i.e., predominantly red in hue and of sufficient tone and saturation). Fifteen samples were either too light in tone (i.e., pink) or were predominantly purple and, therefore, not ruby color in our opinion. Some of these latter stones exhibited a weak color change, typically pinkish purple in fluorescent light and purplish pink under incandescent lighting. These 27 stones $(0.55-5.67 \mathrm{ct})$ represent the core sample on which our detailed gemological study was carried out, as this was the material that we felt to be potentially most significant from a commercial standpoint.

The remaining 16 stones represented a wide range of colors (including violet, violetish blue, reddish purple, and pinkish purple faceup, most with a distinct unevenness of color-e.g., light blue with patches of pink, violet with purplish pink areas, and yellow with pink patches; figure 3). According to Mr. Pollack, these were the unsatisfactory results of early experi-

Figure 3. These stones, ranging from 0.55 to $3.35 \mathrm{ct}$, represent some of the less successful results of early experimentation to produce pink-to-red diffused color in corundum. Photo by Shane F. McClure.

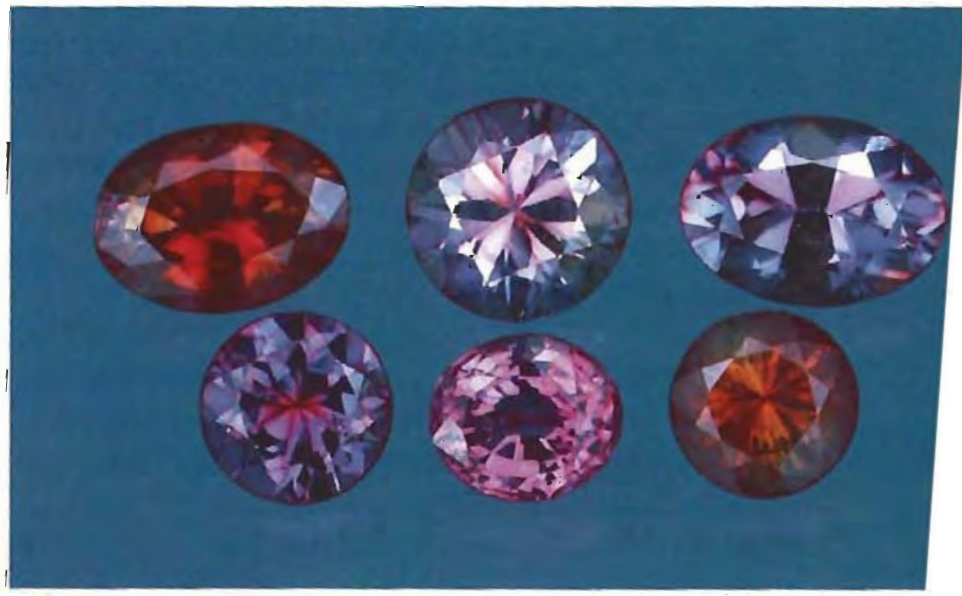


mentation. Although the gemological properties of all were tested, they are not part of the core sample and will be mentioned only briefly where appropriate in the following discussion.

The 27 core samples were first subjected to standard gemological testing. Refractive-index readings were taken on the table facets with a Duplex $\Pi$ refractometer and a near sodium-equivalent light source. Stones exhibiting readings over the limit $(1.80+)$ of the conventional refractometer were tested on a refractometer fitted with a cubic zirconia hemicylinder and using an appropriate contact fluid. Stones in the core sample were examined with a polarizing filter dichroscope, and all test stones were examined in transmitted light with a Chelsea filter. Four-watt long- and short-wave lamps in a controlled, darkened environment were used to determine the ultraviolet luminescence behavior of the test stones. Specific gravity was determined using the hydrostatic weighing method, with three separate sets of readings taken on each stone. The stones were also examined with a microscope in conjunction with diffused, transmitted illumination and immersion (as described by Kane et al., 1990.). Use of a GIA GEM Instruments illuminated immiersion cell produced comparable results.

In addition, we selected seven samples /representing the range of refractive indices observed, with five of "ruby" color) for more sophisticated testing. Energy-dispersive X-ray fluorescence (EDXRF) was performed at GIA using a Spectrace 5000 spectrometer (for more details on the technique see, e.g., Fritsch and Rossman, 1990). The standard conditions for analysis were a tube voltage of $25 \mathrm{kV}$, a current of $0.25 \mathrm{~mA}$, an aluminum filter, and a 200-second life time. For the detection of aluminum, no filter was used, the voltage was $15 \mathrm{kV}$, and the current was 0.15 $\mathrm{mA}$. Electron microprobe (EMP) analyses were performed on these stones at the California Institute of Technology by Paul Carpenter. Optical absorption spectra were recorded on a Hitachi U4001 spectrophotometer, at a resolution of $0.5 \mathrm{~nm}$. X-ray powder diffraction analyses were performed on two of the stones, at a voltage of $50 \mathrm{kV}$ and a current of $40 \mathrm{~mA}$.

\section{GEMOLOGICAL PROPERTIES}

Visual Appearance. The 27 stones in the core sample ranged from medium to dark in tone and included purplish pink, reddish purple to purplish red, and orangy red hues. Faceup, some of the stones appear uniform in color, while others display varying degrees of uneven color distribution (figure 4). The unevenness

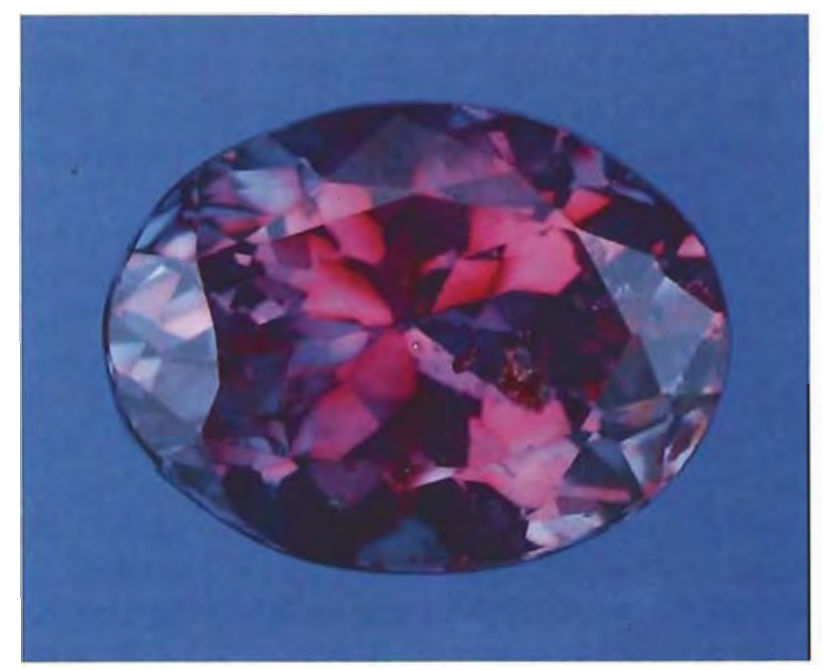

Figure 4. The uneven faceup color of some of the test stones is evident in this 1.60-ct specimen. Photo by Shane F. McClure.

appears to be the result of a complete absence of color on some pavilion facets, probably because of partial removal of the diffusion layer during repolishing.

Some stones displayed a strong orange component when examined in other than the faceup position, for example, through the girdle or the pavilion. This appearance, which in our experience is not typical of either natural or synthetic corundums of similar faceup color, can be attributed to the inherent yellow body color of these stones. In a few instances this yellow substrate color was strong enough to influence the faceup appearance of the stone, making it an orangy red. A similar effect was previously noted where an inherent blue body color underlying a red diffusion layer resulted in a predominantly violet faceup appearance (Koivula and Kammerling, 1991b).

In most cases, the faceup appearance of the 16 "experimental" stones could be explained in large measure by the amount and distribution of the diffusion-produced color. In the case of stones that appeared violet, a thin red diffused layer covered much of the pavilion surface of a stone with a light blue body color. In the case of stones with patchy faceup color, it appeared that much of the diffused color layer had been removed during repolishing. The predominantly yellow stone had so little diffused color that, for the most part, only the original body color was visible.

Refractive Indices. As this property is generally not affected by enhancement processes, we were surprised to find that values for the test samples varied signif- 
icantly from those expected for corundum (typically $1.762-1.770$ ). Of the 27 samples, only one had readings in the normal range. Two gave abnormally high readings that were still within the limits of the refractometer (1.770-1.779 and 1.788-1.798).

A small group (five stones) actually displayed two distinct sets of readings on the table facets. For example, one stone exhibited a distinct set of normal corundum readings (1.762-1.770), but another set of shadow edges gave values of 1.779-1.789. Another such stone gave readings of $1.760-1.768$, and also showed a distinct shadow edge at the upper limit of the instrument. It is possible that the dual readings result from different concentrations of the diffused chromium ion on different areas of the facets being tested. Alternatively, the higher readings may be for the very thin, chromium-rich diffused layer, while the lower-typical corundum-readings are for the untreat. ed substrate just below that layer. A similar situation is sometimes encountered with gamet and glass doublets that have very thin garnet "caps," where both gamet and "substrate" glass readings are observed at the same time.

Significantly, 19 of the stones had values over the limits of the refractometer, that is, $1.80+$. Six of these were tested on a refractometer with a cubic zirconia hemicylinder, which produced readings in the 1.81 to 1.84 range. Although the readings were not distinct enough to permit accurate determinations of birefringence, this appeared to be approximately 0.01 . One of the six stones exhibited a dual reading, that is, one that was over the limits and one that was typical of corundum.

It is interesting to note here that five of the 16 "experimental" stones exhibited refractometer readings within the normal range for corundum, apparently due to the relatively thin diffused color layer on the facet tested. Three stones exhibited two distinct readings, while the remaining eight had single, overthe-limits values. Again, those with the higher readings had a more pronounced diffusion-induced color layer on the surface tested. Although the R.I. values varied significantly, the birefringence was relatively constant and within the range expected of conundum, 0.008-0.010.

Pleochroism. While some of the stones exhibited pleochroism typical of both natural and synthetic corundum of comparable colors, the majority showed atypical dichroism. In most of the "ruby color" stones, in particular, one dichroic color was purplish pink to purplish red and the other was brownish yellow. In our

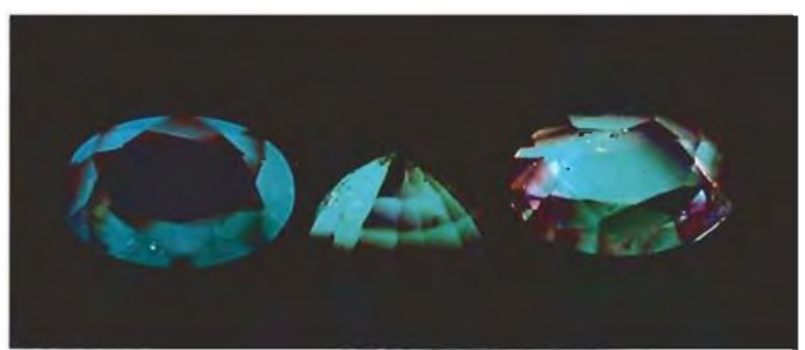

Figure 5. When exposed to short-wave U.V. radiation, all but one of the stones exhibited some degree of patchy surface luminescence, as seen in these 2.25- to 2.81-ct samples. Photo by Shane F. McClure.

experience, the second pleochroic color of comparably colored natural and synthetic rubies ranges from orangy red to orange. It was further noted that the pleochroism was sometimes quite inhomogeneous, with adjacent areas displaying distinctly different pleochroic colors. This inhomogeneity appeared to correlate with variations in the depth of the diffused layer of color due to uneven repolishing.

Chelsea Filter Reaction. All 27 core-sample stones gave a weak to moderate red reaction to the Chelsea color filter, virtually identical to what would be expected of untreated natural or synthetic corundums of comparable body color.

Ultraviolet Luminescence. The 27 core samples had very consistent reactions to long- and short-wave ultraviolet radiation. When exposed to long-wave U.V., most of the stones luminesced a faint to weak orangy red to red. In the authors' experience, these reactions overlap those of natural rubies from various localities as well as those of some flux-grown synthetic nubies. One stone showed a moderate orange fluorescence, a second fluoresced a weak reddish orange, and a third was inert. A close examination of these reactions revealed that the orange component of the luminescence came primarily from the body of the stones, while the red component originated at or near the surface (i.e., from the diffused layer). While this reaction is unlike any we have noted in either natural or synthetic rubies, the underlying orange luminescence was identical to that reported for some blue diffusion-treated sapphires (Kane et al., 1990), as well as for many natural sapphires from Sri Lanka (Webster, 1983).

Short-wave U.V. reactions were even more consistent. The interiors of the vast majority (25) of the sample stones were inert; two luminesced a faint red. However, all but one of the stones exhibited unusual patches of weak to moderate chalky bluish white to 
yellowish white luminescence at the surface (figure 5). In some instances, these luminescent patches were seen to be clearly confined to-and paralleling-the shapes of facets, either singly or in small groups. This is in contrast to the chalky greenish white short-wave U.V. luminescence sometimes displayed by blue diffusion-treated as well as heat-treated sapphires, where the reaction emanates from the entire stone or from irregular areas that do not correspond to specific facets. Patchy blue short-wave luminescence has been noted by the authors in some rubies suspected of having been subjected to high-temperature treatment. In these instances, however, the patchy luminescence was not confined to specific facets or groups of facets.

Absorption Spectra. In general, the absorption features noted with the desk-model spectroscope were similar to those of both natural and synthetic corundums in the pink-to-red-to-purple color range. There were, however, two notable differences. First, the sharp absorption lines at approximately 468.5, 475.0, and $476.5 \mathrm{~nm}$ (Webster, 1983) that are generally pronounced in even medium-toned corundum of these colors were very weak or absent. In addition, the fine absorption lines in the red portion of the spectrum at 659.2, 668.0, and $697.5 \mathrm{~nm}$ (Webster, 1983) were weaker than would be expected in stones with comparable depths of color.

Specific Gravity. The specific-gravity values obtained3.99 to 4.01 -were well within the range for corundum, both natural and synthetic.

Figure 6. Discoid fractures in several of the sample stones provided evidence of high-temperature treatment in general, but they are not specific to the diffusion process. Photomicrograph by Shane $F$. McClure; magnified 15x.

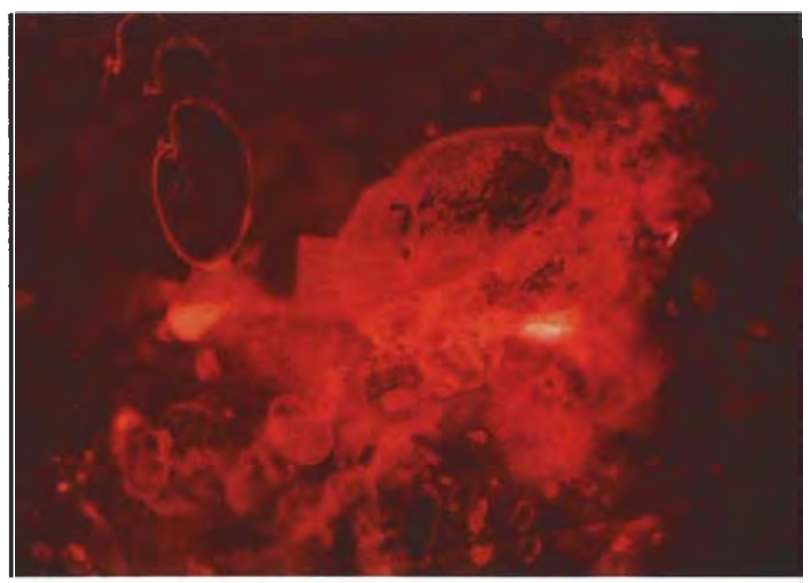

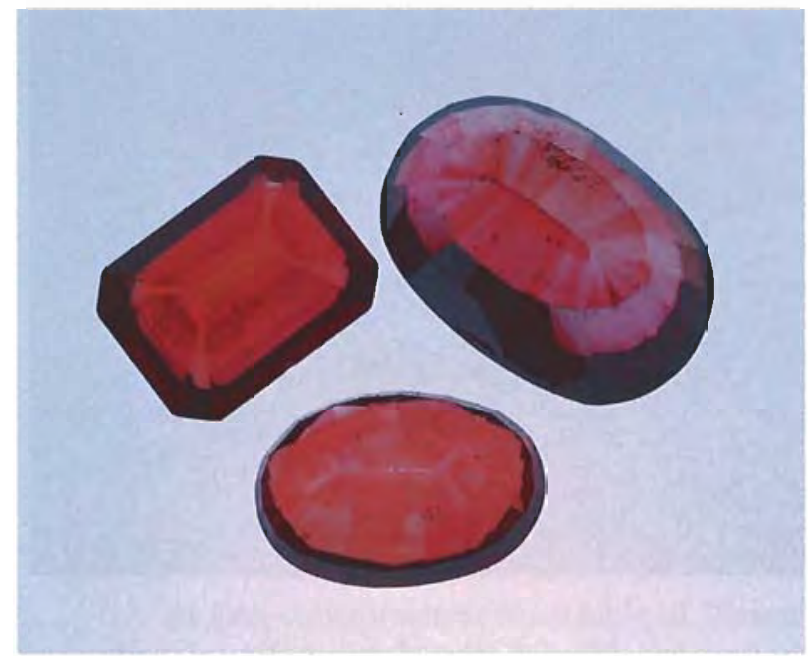

Figure 7. Uneven coloration from one facet to another was the most prevalent feature notedwith low magnification or, in some cases, with the unaided eye-in the diffusion-treated corundums in this study. Photo, taken in diffused transmitted light without immersion, by Shane F. McClure.

Magnification. Examination of these stones with magnification proved to be one of the most valuable and consistent tests for detecting treatment. We observed features typical of high-temperature corundum enhancements in general, as well as those associated with diffusion treatment in particular. We also noted characteristics that had not previously been reported in blue diffusion-treated stones.

The features typical of heat treatment- that is, discoid fractures (figure 6), melted crystal inclusions, and sintered surfaces - were seen in many of the samples. In the authors' experience, such features are significantly less common in heat-treated rubies than in heat-treated sapphires. However, we do not feel that this observation could be used effectively as a criterion for the identification of diffusion treatment because they only indicate that the stones have been exposed to high temperatures.

Among the features specifically associated with diffusion treatment (see, e.g., Kane et al., 1990), most prevalent was uneven coloration from one facet to another. Whereas most blue diffusion-treated sapphires reveal this patchiness only with immersion, we observed it easily in many-but not all-of the pink-to-red sample stones using only diffused transmitted light (and, in some cases, even without magnification; figure 7). We also noted that the unevenness of color was more pronounced than is usually apparent in most blue-treated stones, with relatively more 


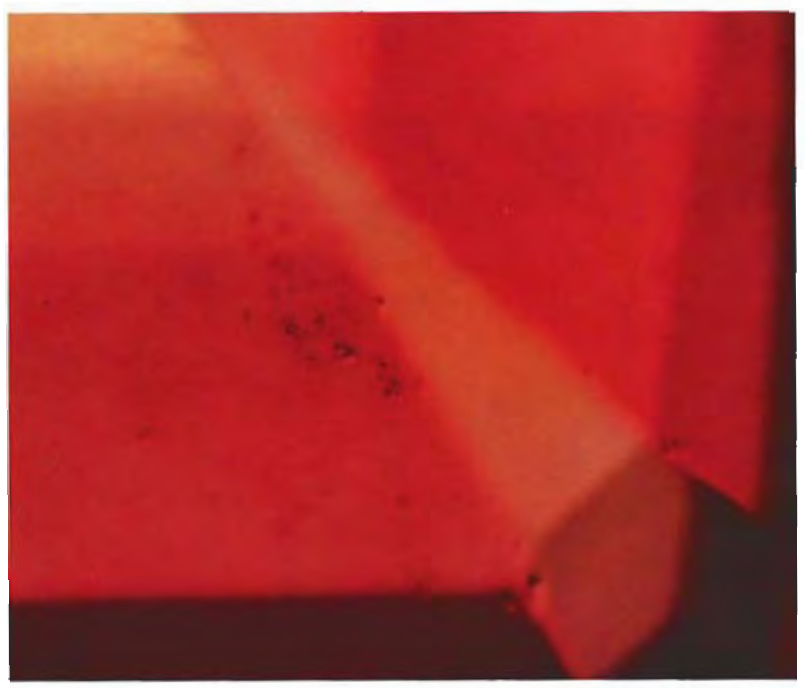

Figure 8. In general, the predominantly pink-tored-to-purple diffusion-treated stones showed more areas that were totally devoid of diffused color than have been noted in blue diffusion-treated stones. Photomicrograph by Shane F. McClure; magnified $28 \times$.

facets being totally devoid of color (figure 8). This is due to a relatively thinner layer of diffused color and/or excessive repolishing.

As with blue diffusion-treated corundum, stones in our test sample displayed "bleeding" - concentrations of color in surface-reaching cavities and fractures (figure 9). One stone had a fracture extending from the table to the surface of the pavilion near the

Figure 9. Some of the stones in the test sample displayed "bleeding," or concentrations of color, in surface-reaching cavities. Photomicrograph by Shane F. McClure; magnified 28x.

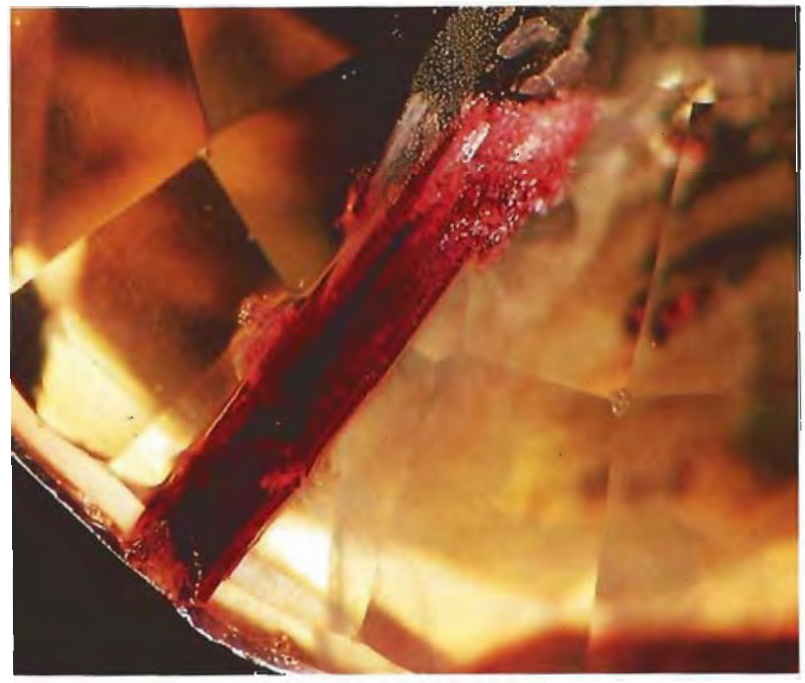

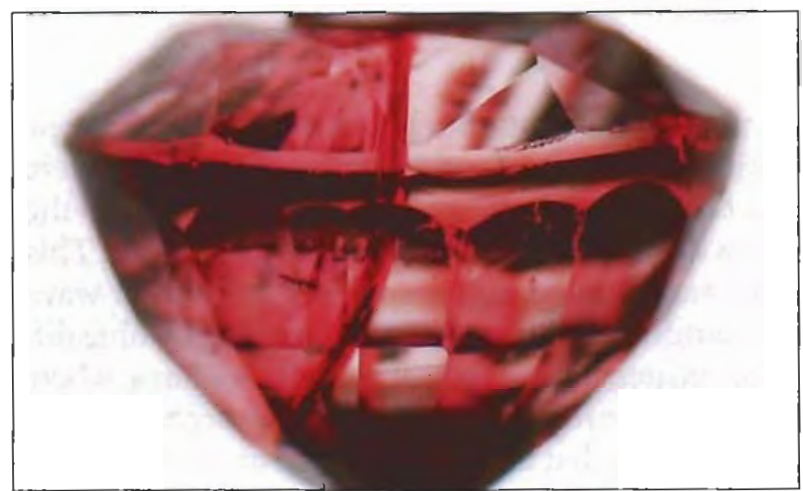

Figure 10. A concentration of diffused color is quite apparent in the large fracture that traverses this stone from the table to near the culet. Photomicrograph by Shane F. McClure; magnified $17 x$.

culet that exhibited such diffused color along its entire length (figure 10).

Many of the stones also displayed varying degrees of surface and near-surface damage that has not been seen in the blue diffusion-treated sapphires examined to date. Most common were small groups of minute spherical voids visible just below the surface (figure 11). Where these broke the surface, small pits resulted (figure 12). In addition, these clusters of voids and pits were invariably surrounded by concentrations of the diffused color (figure 13). Note that Brown et al. (1990) reported the presence of numerous small "bubbles" in the diffusion layers on a sample of red diffusion-treated flame-fusion synthetic sapphires.

Figure 11. Small groups of minute spherical voids within the diffused color layer were visible in many of these stones. Photomicrograph by Shane F. McClure; magnified $40 \times$.

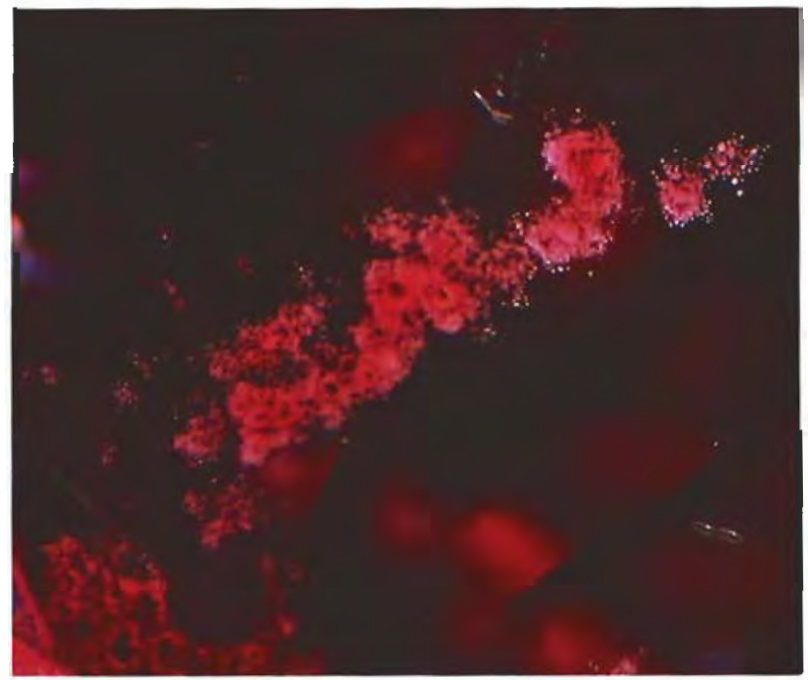




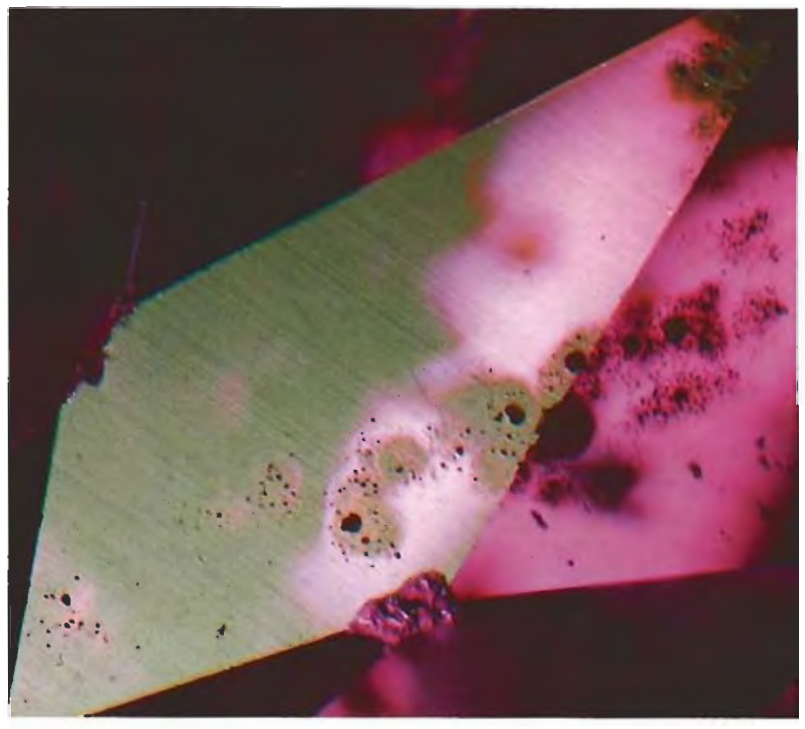

Figure 12. With reflected light, pits can be seen where small voids like those shown in figure 11 break the surface of the stone. Photomicrograph by Shane F. McClure; magnified 28x.

Figure 13. Concentrations of diffused color invariably surrounded the small pits and spherical voids in the diffused layer. Photomicrograph by Shane F. McClure; magnified $40 \times$.

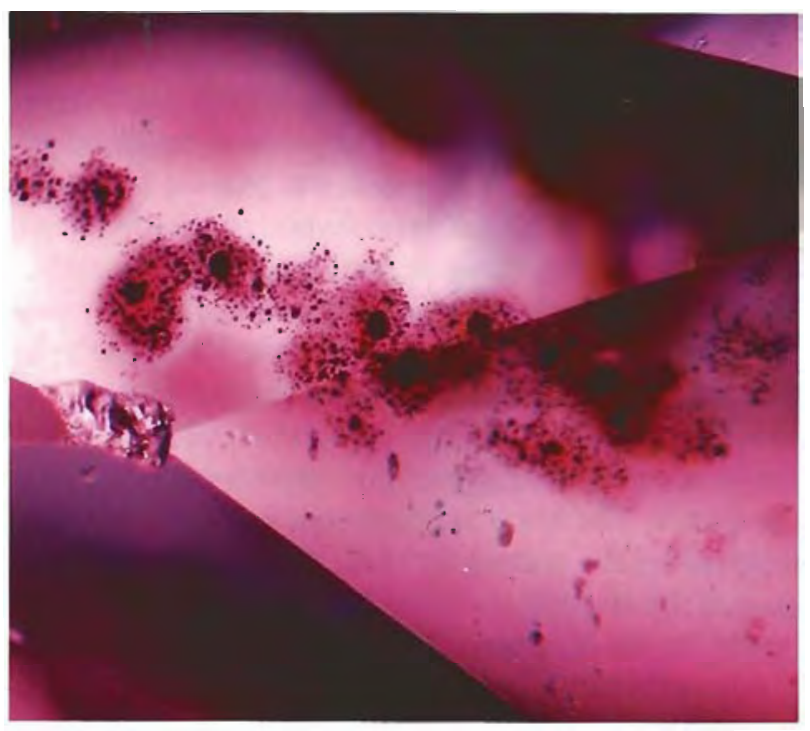

Also in the near-surface area, we saw dense concentrations of very small, white inclusions covering entire facets (figure 14). To the unaided eye, these gave the appearance of a poor polish, although in reflected light the other-than-surface nature became evident.

Immersion. With this technique, uneven coloration was revealed in those stones where it was not evi-

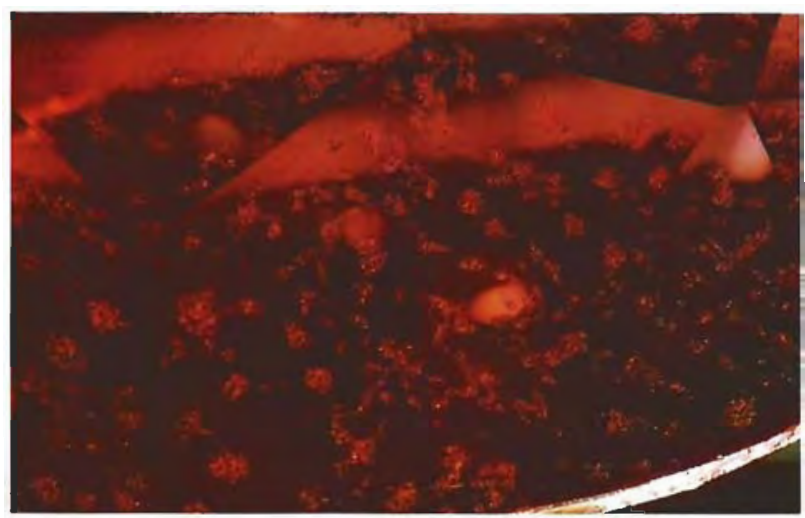

Figure 14. Dense concentrations of very small, white inclusions were often noted in the near-surface areas, covering entire facets. Photomicrograph by Shane F. McClure; magnified 27x.

dent with magnification only, and it became much more evident in the others (figure 15). We also noted, however, that the color reinforcement of facet junctions was significantly more subtle than in blue diffusion-treated corundum (Kane et al., 1990). In some instances, virtually no color outlining was observed. This occurred with stones that retained a fairly even diffused layer after repolishing. The stones in the core sample that fit this description were predominantly dark red, although this could conceivably also be the case with evenly treated pink or purple stones. The

Figure 15. The uneven distribution of diffused color in many of the test stones was easily seen when immersion (here, in methylene iodide) was used in conjunction with diffused transmitted light. Photo by Shane F. McClure.

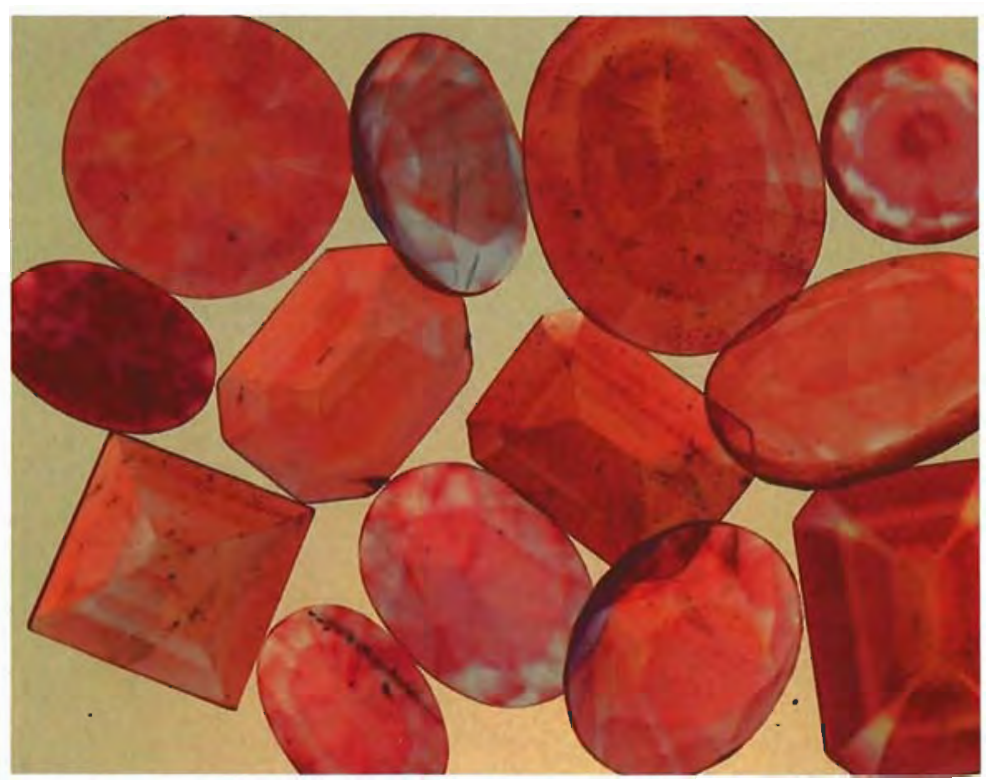




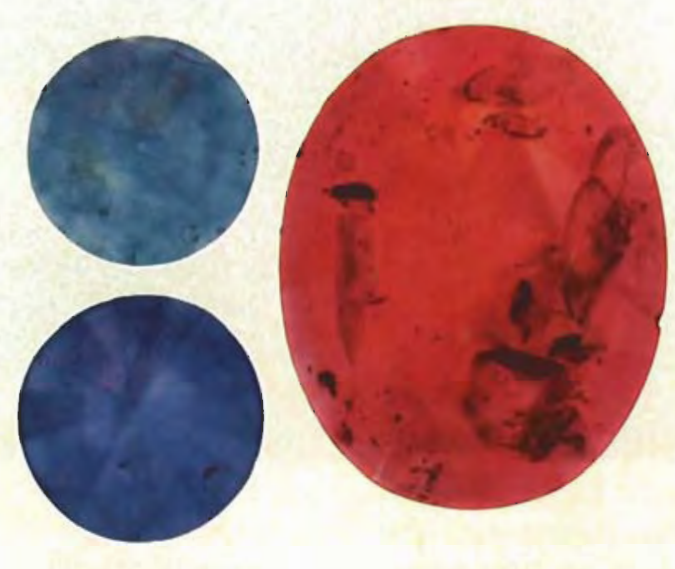

Figure 16. Color reinforcement of facet junctions is much more subtle-and, in some cases, completely absent-in predominantly pink, red, and purple diffusion-treated stones when compared to typical blue diffusion-treated sapphires. Photo by Shane F. McClure.

subtlety or absence of this feature is particularly evident when a red diffusion-treated stone is examined next to a blue diffusion-treated one (figure 16).

Several features we observed in these stones while they were immersed were similar to ones reported for blue diffusion-treated sapphires. The most notable of these was the much higher relief of the diffusiontreated stones when compared to natural or synthetic rubies (figure 17). This feature is extremely helpful in identifying this material when comparison stones are available. Also seen in this material, as it is in the blue, is a dark ring around the girdle of some of the stones (figure 18).

Figure 17. With immersion (here, in methylene iodide), the significantly greater relief of the diffusion-treated stone (center) as compared to synthetic (left) and natural (right) ruby is readily apparent. Photo by Shane F. McClure
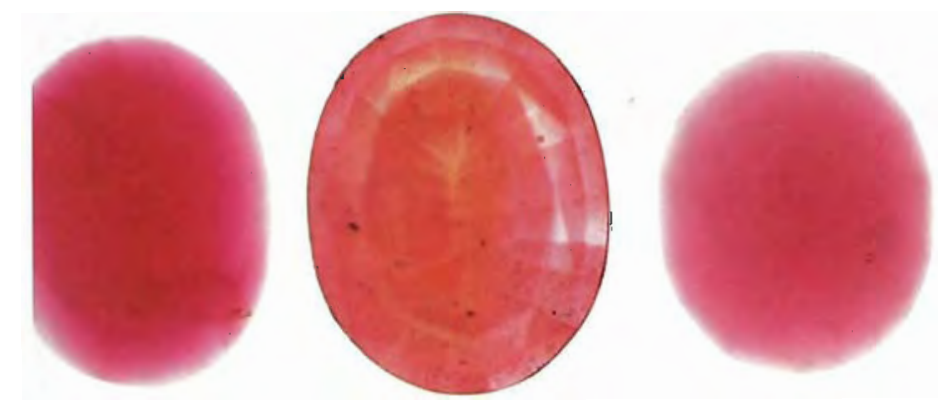

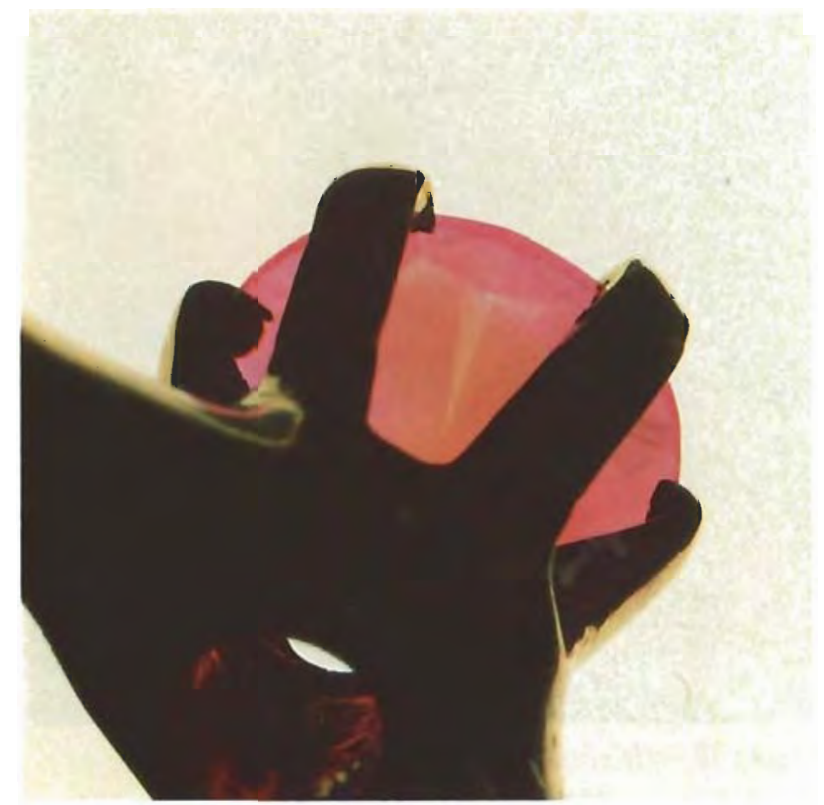

Figure 18. A dark ring of color is visible around the girdle of this 0.56-ct mounted diffusion-treated stone immersed (in methylene iodide). Note that some patchiness of color can also be seen between the prongs of the mounting. Photo by Shane F. McClure.

As was the case with the blue diffusion-treated sapphires examined by Kane et al. (1990), methylene iodide was the most effective immersion medium for detecting diagnostic features in the current test sample. However, we also obtained good results for most stones with water and glycerine (see, e.g., figure 19).

One curious feature noted in several stones was the presence of a relatively deep, pale blue or purple diffused layer underlying the near-surface pink to red diffusion color (figure 20). Immersion also revealed the presence of irregular yellow zones within some of the stones. The latter is consistent with information supplied by the treater that pale yellow sapphires are used as the starting material, but we do not know the reason for the blue layer. Koivula et al. (1992b) recently reported that yellow sapphires are being purchased in large quantities in Sri Lanka for use in both heat and diffusion treatment. During a visit to Sri Lanka in mid1992, the senior author was told that demand for these stones had resulted in significant price increases.

\section{CHEMICAL ANALYSIS, OPTICAL ABSORPTION, AND X-RAY POWDER DIFFRACTION}

Chemical Analysis. We compared chemical analyses obtained using EDXRF and electron microprobe techniques on the seven samples mentioned earlier (table 
1). Besides aluminum and oxygen, the other elements present in concentrations that can be reliably measured with both techniques are chromium, iron, and titanium. Small amounts of gallium were detected in all samples by EDXRF. Silicon, magnesium, and vanadium were analyzed for but not detected.

The major finding is that chromium concentrations for these stones-from more than $7 \mathrm{wt} \%$ to almost 17 wt. \% $\mathrm{Cr}_{2} \mathrm{O}_{3}$ as measured by EMP-are much higher than those measured for natural or synthetic ruby (which, in our experience, are typically $\left.0.2-2.0 \mathrm{wt} . \% \mathrm{Cr}_{2} \mathrm{O}_{3}\right)$. Although some natural or synthetic stones might have higher chromium concentrations (see, e.g., Henn et al., 1990), such stones are usually very dark, significantly darker than any of our diffusion-treated samples. The high chromium content measured in the diffusion-treated stones is easily explained: The apparent color is not homogeneously distributed throughout the stone; rather, it is limited to a very thin layer in which the coloring agentchromium-must be concentrated. Concentrations of other elements such as $\mathrm{Ga}, \mathrm{Fe}$, and $\mathrm{Ti}$, which do not participate in the red coloration, are typical of those measured in some natural rubies. Therefore, EDXRF is helpful in proving that the diffusion treatment was applied to natural—not synthetic-sapphires.

A significant difference between the two methods of chemical analysis used for this study, and one that proved uniquely valuable in this application, is that the microprobe takes measurements at a much shallower depth (only a few micrometers) than does EDXRF (about 100 micrometers). Thus, the EDXRF results reflect an average composition for the surface diffusion layer, where most of the chromium is concentrated,

Figure 19. With immersion in water, the patchiness of color typical of diffusion treatment is readily apparent in the 1.96-ct red stone, but is very subtle in the 2.14-ct blue diffusion-treated stone. Photo by Shane F. McClure.

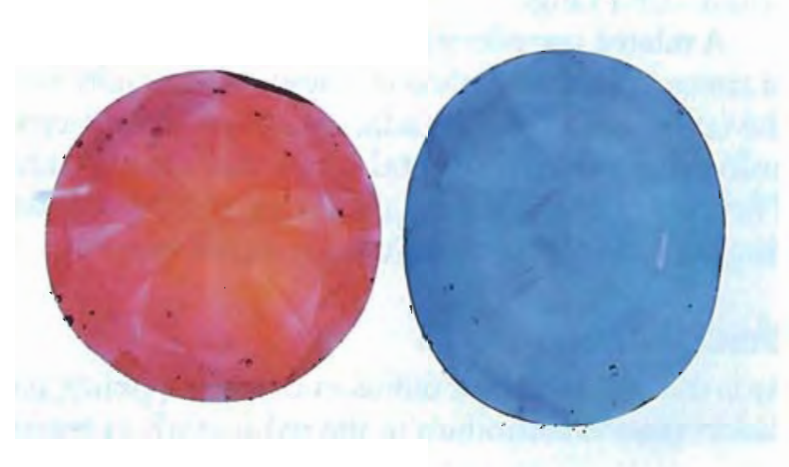

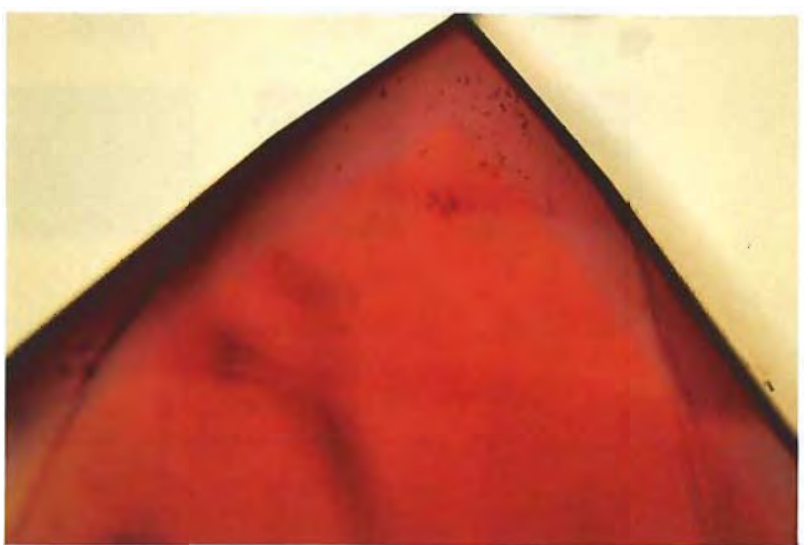

Figure 20. Several of the sample stones revealed $a$ relatively deep, pale blue or purple diffused layer underlying the near-surface pink-to-red diffusion color. Photomicrograph by Shane F. McClure; magnified $30 \times$.

plus the region beneath, where less of the chromium has penetrated. Consequently, the microprobe results show values appreciably higher for $\mathrm{Cr}_{2} \mathrm{O}_{3}(7.42-16.83$ wt.\%) and lower for $\mathrm{Al}_{2} \mathrm{O}_{3}(83.25-92.60 \mathrm{wt} . \%)$ than those revealed by EDXRF $(4.18-13.16 \mathrm{wt} \%$ and 85.85-95.49 wt.\%, respectively).

Note also the variation in EMP:EDXRF chromium concentration ratios for different stones. This is not necessarily caused by a variation from stone to stone in the speed of diffusion; a more likely explanation is that more material was removed during repolishing from the tables of certain stones.

The titanium concentrations measured by the two techniques are basically comparable. However, the iron concentrations determined by EDXRF are greater than (sometimes only marginally, but up to almost double) those measured with the electron microprobe. This is opposite the behavior of the chromium concentrations. Although several explanations could be ventured, we are not certain of the cause of this difference.

Optical Absorption. Optical absorption spectra of three "ruby-color" samples of diffusion-treated corundum were taken in a random orientation. The broad bands centered at approximately 410 and $560 \mathrm{~nm}$, which determine the color of the stone, are similar to those observed in natural and synthetic rubies. The most distinct "chromium lines" - at 692 and 694 $\mathrm{nm}$-and other sharp bands seem weaker and wider than in the spectra of natural rubies. The sharp features seen in all naturally colored rubies at about 467 and $474 \mathrm{~nm}$ are difficult to discern, and those expected 
TABLE 1. Electron microprobe ${ }^{a}$ and EDXRF analyses of seven selected diffusion-treated corundums.

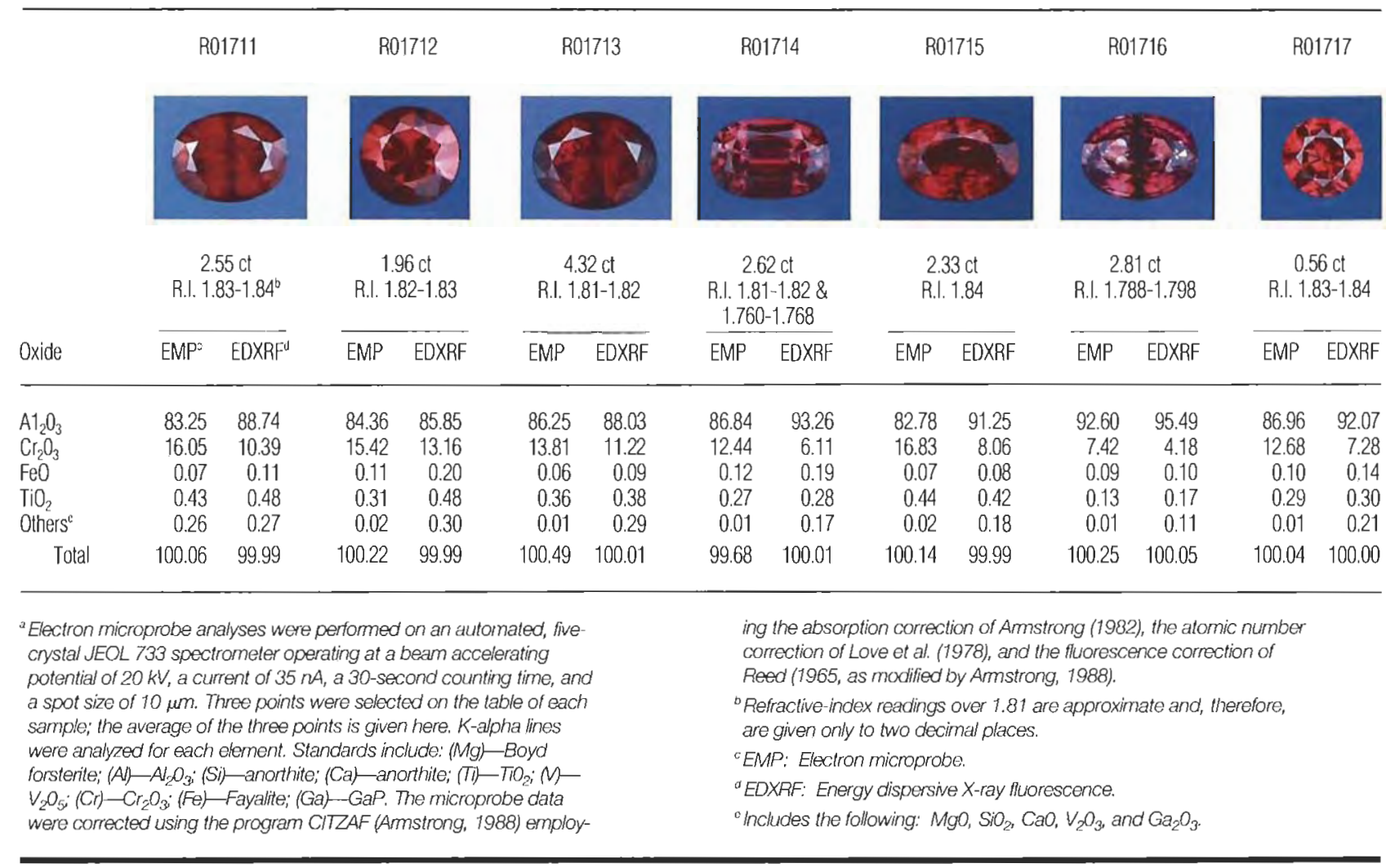

at 658 and $668 \mathrm{~nm}$ are not detectable. In two of the three samples, there seems to be some absorption on the low-energy side of the 692-694 nm doublet, with an apparent maximum at about $700 \mathrm{~nm}-\mathrm{a}$ feature that has never been reported in untreated rubies.

X-ray Powder Diffraction. Because of the exceptionally high chromium concentrations detected in the near-surface areas, the question arose as to whether this layer still retained the structure of corundum. Therefore, we selected two stones for X-ray powder diffraction analysis. For the scrapings, we chose areas with relatively deep color penetration to insure that the powder sample was removed from a treated portion. In both instances, the resulting patterns were identical to standard patterns for corundum.

\section{DURABILITY AND STABILITY}

In the Kane et al. (1990) study of blue diffusion-treated sapphires, the treatment layer was shown to be unaffected by such standard cleaning procedures as ultrasonic and steam cleaning, and boiling in a detergent solution. That investigation also showed that the heat and chemicals used in jewelry repair proce- dures could result in minor to moderate surface etching, as would be expected with corundum generally. Given the findings of this study, it can be expected that the diffusion-treated stones described herein would exhibit similar durability and stability results.

Of particular importance with any diffusion-treated stone is the fact that repolishing or recutting could remove some or all of the diffused layer, resulting in a lightening or total loss of color. Given the observed shallowness of color penetration in the present study stones-as well as the many areas where the diffused color layer has apparently been completely removed in repolishing - this precaution is especially pertinent to diffusion-treated stones in the pink-to-red-topurple color range.

A related consideration is that the removal of color zones from the pavilion of a stone-especially near the culet-generally has a far greater effect on faceup color than their removal from the crown area. Therefore, we recommend against repolishing or recutting pavilion facets on diffusion-treated stones.

\section{DISCUSSION}

As is the case with blue diffusion-treated sapphires, diffusion-treated conundum in the red-to-pink-to-purple 
color range can also be readily identified by standard gemological testing.

As with blue diffusion-treated stones, an important diagnostic feature is the uneven coloration from one facet to another, including areas where the diffused color layer has been completely removed in repolishing. Because this type of color anomaly was easier to detect in the current test sample than it has been with blue diffusion-treated stones, immersion was less critical, although in all three media used, it did make the patchiness more obvious. However, several stones in this sample showed very little patchiness and facet reinforcement. Moreover, because refinements in the treatment process are inevitable, all corundums-regardless of color-should be routinely examined in immersion. Also typical of the treatment is a bleeding of diffused color in surface cavities and surface-reaching fractures.

Concentrations of color along facet junctions may be seen in diffusion-treated stones in the color range covered by this study, but they are likely to be more subtle or even absent in some instances, making this a less reliable diagnostic feature. When present, however, such.concentrations do provide proof of diffusion treatment.

Also noted with magnification were small voids within the color-diffused layer, just below and/or breaking the surface of the stones. Similar features have been noted in stones with orange faceup color, resulting from a red diffusion color overlying yellow synthetic sapphire (Brown et al. 1990). The presence of such voids in a surface color layer--especially where they are surrounded by concentrations of color-can also be considered diagnostic of diffusion treatment.

Unlike blue diffusion-treated stones, anomalous refractometer readings can provide additional evidence of diffusion treatment where chromium is the diffused chromophore. Such readings include atypically higher values than expected of corundum, including over-the-limits readings, as well as multiple readings on a single facet. Such anomalous readings may be quite confusing to some gemologists. The high R.I. values are most likely due to the unusually high chromium concentrations in the surface-diffused layers. Relatively high refractive indices have also been found to correlate with high chromium concentrations in natural ruby from Malawi, which were very dark (Henn et al., 1990), and emeralds (e.g., those from the Swat Valley of Pakistan-Gübelin, 1982; Bowersox and Anwar, 1989).

The high chromium concentration measured near the surface of these diffusion-treated rubies also explains their very weak luminescence. Extremely high chromium concentrations are responsible for what is known as "concentration quenching" of luminescence (Waychunas, 1988). This phenomenon occurs when $\mathrm{Cr}_{2} \mathrm{O}_{3}$ exceeds $0.6 \mathrm{wt}$.\% in corundum, with a corresponding decrease in luminescence as the $\mathrm{Cr}^{3+}$ concentration increases (Dubois-Fournier, 1989).

The subdued luminescence is not diagnostic of these treated stones, since natural rubies from several localities (e.g., Umba Valley, Tanzania) may also show very weak reactions. What is indicative of the treatment when present, however, is a superficial, chalky bluish white to yellowish white short-wave luminescence confined to and paralleling individual facets or groups of facets.

Also of value in detecting $\mathrm{Cr}^{3+}$-diffusion treatment are the abnormally weak spectral absorption features for the respective apparent depths of color. These include weak or absent lines in the $475-\mathrm{nm}$ area and in the far red.

\section{CONCLUSIONS}

It is important to keep in mind that the properties described in this report are based on a relatively small sample of diffusion-treated faceted stones in the pinkto-red-to-purple color range. Furthermore, the treater, Richard Pollack, has indicated that experimentation is continuing with the goal of both increasing the depth of penetration of the diffused color layer and minimizing surface damage. It is believed that other laboratories are also experimenting with diffusion treatment in this color range. Therefore, the extent and/or presence of many of the above features-especially those noted with magnification-may vary. For example, deeper penetration of the color-causing chromium ion, coupled with careful repolishing, could result in stones with little or no patchiness of color; that is, there might be no facets that are devoid of diffusion color. A deeper diffusion layer could also facilitate the removal during repolishing of the surface damage noted herein. Color reinforcement along facet junctions might be altered as well. Variations in the depth of penetration would, in turn, quite possibly alter the ultraviolet luminescent reactions, for example, perhaps partially or totally masking the underlying orange fluorescence to long-wave U.V. seen in some of the test stones.

With the above caveats in mind, the diffusiontreated corundums described in this article are not difficult to identify. Diagnostic features include the following lat least one of which was present in all stones examined): 
- Uneven or patchy facet-to-facet coloration and a dark ring around the girdle. In many cases, this was noted without magnification, with only immersion and diffused transmitted light.

- Color concentrations along facet junctions and/or in surface-reaching fractures and cavities, noted with magnification. This feature was best noted with diffused transmitted illumination.

- Spherical voids just below the surface and within the diffusion layer, usually surrounded by color concentrations and seen with magnification.

- Dense concentrations of very small, white inclusions just under the surface of the stones and covering entire facets. This feature is best seen with magnification and darkfield illumination.

- High relief of diffused stones when compared to natural or synthetic rubies in immersion.
Other key features noted in the test sample include the following:

- Weak to moderate, chalky bluish white to yellowish white short-wave ultraviolet surface luminescence. This reaction may be clearly confined to and parallel individual facets or groups of facets.

- Anomalous refractive index readings, including multiple readings on individual facets and readings overthe limits of the conventional refractometer $(1.80+)$.

- Atypical dichroism, with one color being a distinct brownish yellow as opposed to the expected orangy red to orange.

- Absorption characteristics that are weaker than what would be expected for either natural or synthetic rubies or fancy sapphires of comparable depth of color.

\section{REFERENCES}

Armstrong J.T. (1982) New ZAF and alpha-factor correction procedures for the quantitative analysis of individual microparticles. In K.F.J. Heinrich, Ed., Microbeam Analysis-1982, San Francisco Press, San Francisco, CA, pp. 175-180.

Armstrong J.T. (1988) Quantitative analysis of silicate and oxide materials: Comparison of Monte Carlo, ZAF and Phi (rho z) procedures. In D.E. Newbury, Ed, Microbeam Analysis-1988, San Francisco Press, San Francisco, CA, pp, 239-246.

Bowersox G.W., Anwar J. (1989) The Gujar Killi emerald deposit, Northwest Frontier Province, Pakistan. Gems \&) Gemology, Vol. 25, No. 1, pp. 16-24.

Brown G., Kelly S.M.B., Beattie R., Bracewell H. (1990) Gemmology study club lab reports: Diffusion coated synthetic sapphire. Australian Gemmologist, Vol. 17, No. 8, pp. 326-328.

Carr R.R., Nisevich S.D. (1975) Altering the appearance of sapphire crystals. United States patent 3,897,529, filed December 15, 1969 , issued July 29, 1975.

Crowningshield R. (1979) Developments and highlights at GIA's lab in New York. Gems e) Gemology, Vol. 16, No. 7, pp. 194-196.

Diffusion: 80,000 carats in Asia (1991). Jewellery News Asia, No. 87 , November, p. 77

Diffusion-treated red conundum in HK (1992). Jewellery News Asia, No. 96, August, pp. 96,98.

Dubois-Foumier J. (1989) A contribution to the identification of ruby by detecting various trace elements [in French]. D.U.G. report, Nantes University, $201 \mathrm{pp}$

Federman D. (1992) Diffusion sapphire, beyond the pale. Modern leweler, Vol. 91, No. 2, February, pp. 76-79.

Fritsch E., Rossman G.R. (1988) An update on color in gems, part 3: Colors caused by band gaps and physical phenomena. Gems e) Gemology, Vol. 24, No. 2, pp. 81-102.

Fritsch E., Rossman G.R. (1990) New technologies of the 1980s. Gerns \&) Gemology, Vol. 26, No. 1, pp. 64-75.

Gübelin E.J. (1982) Gemstones of Pakistan: Emerald, ruby, and spinel. Gems $\Leftrightarrow$ ) Gemology, Vol. 18, No. 3, pp. 123-139.

Hargett D. (1991) Gem trade lab notes: Diffusion-treated sapphires in fine jewelry. Gems et) Gemology, Vol. 27, No. 3, pp. 178-179.

Henn U., Bank H., Bank F.H. (1990) Red and orange corundum (ruby and padparadscha) from Malawi. Journal of Gemmology, Vol. 22, No. 2, pp. 83-89.
Kammerling R.C., Koivula J.l., Kane R.E. (1990) "Deep" diffusion treatment of corundum. ICA Early Warning Laboratory Alert, No. 32, February 16.

Kammerling R.C., Moses T., Kane R.E. (1992) Blue diffusion-treated synthetic sapphires. ICA Early Warning Laboratory Alert, No. 55 , June 2.

Kane R.E., Kammerling R.C., Koivula J.I., Shigley J.E., Fritsch E. (1990) The identification of blue diffusion-treated sapphires. Gems el) Gemology, Vol. 26, No. 2, pp. 115-133.

Koivula J.I., Kammerling R.C. $\{1990\}$ Gem news: Diffusion-treated corundum. Gems es Gemology, Vol. 26, No. 1, pp. I00-101.

Koivula J.I., Kammerling R.C. (1991a) Gem News: More on diffusiontreated sapphires. Gems $\Theta$ Gemology, Vol. 27, No. 1, p. 53.

Koivula J.I., Kammerling R.C. (1991b) Gem News: More experimentation with blue diffusion-treated sapphires. Gems \&) Gemology, Vol. 27, No. 3, p. 187.

Koivula J.1., Kammerling R.C. (1991c) Gem News: ... and red stones too. Gems ev Gemology, Vol. 27, No. 3, pp. 187-188.

Koivula J.I., Kammerling R.C., Fritsch E. (1992a) Gem News: Update on diffusion-treated sapphires. Gems e Gemology, Vol. 28, No. 1, pp. 62-63.

Koivula J.I., Kammerling R.C., Fritsch E. (1992b) Gem News: Sri Lanka: Update on gem production. Gems et Gemology, Vol. 28, No. 4, pp. 273-274.

Lithiby J. (1992) Lab report: Surface-diffused synthetic sapphire. JewelSiam, Vol. 3, No. 5, September-October, p. 78.

Love G., Cox M.G., Scott V.D. (1978) A versatile atomic number correction for electron-probe microanalysis. Journal of Physics D, Vol. 11, pp. 7-27.

Reed S.J.B. (1965) Characteristic fluorescence correction in electronprobe microanalysis. British Journal of Applied Physics, Vol. 16, pp. 913-926.

Waychunas G.A. (1988) Luminescence, X-ray emission and new spectroscopies. In F. Hawthome, Ed., Reviews in Mineralogy, Vol. 18: Spectroscopic Methods in Mineralogy and Geology. Mineralogical Society of America, Washington, DC, pp. 639-698.

Webster R. (1983) Gems, Their Sources, Descriptions and Identification, 4th ed. Revised by B.W. Anderson, Butterworths, London. 